\title{
Escola e participação juvenil: é possível esse diálogo?
}

\section{School and Youth participation: Is this dialogue possible?}

\author{
Juarez Dayrell $^{1}$ \\ Nilma Lino Gomes ${ }^{2}$ \\ Geraldo Leão ${ }^{3}$
}

\begin{abstract}
RESUMO
A participação social dos jovens depende de como a sociedade oferece oportunidades nas quais eles possam se envolver em experiências participativas e se informarem sobre as possibilidades nesse campo. A partir dos dados de uma pesquisa nacional sobre a participação social da juventude brasileira, discutese aqui o papel que a experiência escolar dos jovens vem desempenhando nesse processo na Região Metropolitana de Belo Horizonte. De acordo com os dados apresentados, os estabelecimentos de ensino atuam muito timidamente nesse campo, o que parece ser o resultado, tanto das concepções que orientam a organização escolar, como da realidade social que restringe os canais de participação social e política dos jovens brasileiros. O artigo apresenta alguns dados sobre a condição juvenil na Região Metropolitana de Belo Horizonte, em seguida analisa as representações juvenis sobre a participação social evidenciados na pesquisa. Por fim, o artigo discute o papel da escola como fomentadora de experiências participativas entre os seus alunos.

Palavras-chave: juventude; escola; participação social.
\end{abstract}

\begin{abstract}
1 Professor Adjunto da Faculdade de Educação da Universidade Federal de Minas Gerais (UFMG). Doutor em Educação/Universidade de São Paulo (USP). Coordenador Geral do Observatório da Juventude da Faculdade de Educação da Universidade Federal de Minas Gerais (FAE -UFMG), Brasil.

2 Professora Adjunta da Faculdade de Educação da Universidade Federal de Minas Gerais (UFMG). Doutora em Antropologia Social/ Universidade de São Paulo (USP). Integrante da coordenação do Observatório da Juventude da Faculdade de Educação da Universidade Federal de Minas Gerais (FAE - UFMG). Coordenadora Geral do Programa Ações Afirmativas na Universidade Federal de Minas Gerais (UFMG), Brasil.

3 Professor Adjunto da Faculdade de Educação da Universidade Federal de Minas Gerais (UFMG). Doutor em Educação/ Universidade de São Paulo (USP).. Integrante da coordenação do Observatório da Juventude da Faculdade de Educação da Universidade Federal de Minas Gerais (FAE - UFMG), Brasil.
\end{abstract}


The social participation of young people depends on the way society provides opportunities in which they can involve in participatory experiences and inform themselves about the possibilities in this field. Based on the data of a national research about the social participation of the Brazilian youth, this paper aims at discussing the role that young people school experience has fulfilled in this process Belo Horizonte Metropolitan. According to the presented data, the schools have shyly acted in this field, which seems to result both from the conceptions that guide the school organization and the social reality that narrows the political and social participation of the Brazilian young people. This paper presents data on the young people situation at Belo Horizonte Metropolitan Region and analyzes the youth representation towards the social participation demonstrated in the research. Finally, it discusses the school role inciting participatory experiences among its students.

Keywords: youth; school; social participation.

\section{Introdução}

Nos últimos anos, o debate em torno da baixa participação social da juventude resulta em visões fatalistas da "juventude alienada" e posições prescritivas que acenam para um ideal de participação juvenil que não dialoga, considerando as condições efetivas para o seu engajamento em ações sociais e políticas. Assim, é necessário colocar em questão o contexto em que os jovens vêm exercitando de alguma forma a sua inserção social: quais são as circunstâncias sociais e econômicas e qual a sua interferência nas experiências de participação dos jovens brasileiros? Quais as condições e os espaços para a sua possível participação social e política? A experiência juvenil nesse contexto encontra estímulos à participação?

Além disso, torna-se fundamental analisar se o contexto educacional interfere ou não nesse movimento. Nos limites desse artigo, nos propomos a desenvolver uma reflexão sobre a participação juvenil a partir de uma pesquisa realizada na Região Metropolitana de Belo Horizonte (RMBH), ${ }^{4}$ buscando apro-

4 As reflexões são baseadas nos dados locais e nacionais da investigação: Juventude Brasileira e Democracia: participação, esferas e políticas públicas, na sua versão quantitativa, através da pesquisa de opinião e na versão qualitativa, através de cinco Grupos de Diálogo envolvendo 122 jovens, ambos realizados entre julho de 2004 e novembro de 2005. A pesquisa, coordenada pelo IBASE e PÓLIS, foi desenvolvida em oito regiões metropolitanas brasileiras e contou com o apoio financeiro do IDRC - International Development Research Centre/Canadá e do CPRN - Canadian Policy Research Networks/Canadá. Em Belo Horizonte, a pesquisa foi coordenada pelo Observatório da Juventude da UFMG (www.fae.ufmg/objuventude). 
fundar especificamente o papel que a experiência escolar dos jovens vem desempenhando nesse processo. Ou seja, nos perguntamos em que medida o modelo de organização escolar e suas dinâmicas produzem um ambiente propício para o desenvolvimento de experiências de participação juvenil.

\section{A condição juvenil na Região Metropolitana de Belo Horizonte.}

Tendo em vista os limites desse artigo, abordamos aqui a juventude a partir da noção de condição juvenil. Esse conceito diz respeito ao modo como uma sociedade constitui e atribui significado a esse momento do ciclo da vida, no contexto de uma dimensão histórico-geracional, mas também à sua situação, ou seja, o modo como tal condição é vivida a partir dos diversos recortes referidos às diferenças sociais - classe, gênero, etnia, etc. (ABRAMO, 2005; MARGULIS, 2000). Nessa parte apresentamos brevemente alguns aspectos da condição juvenil na RMBH.

Um primeiro aspecto é a relação familiar. Os dados da pesquisa de opinião $0^{5}$ apontam que a grande maioria dos entrevistados e das entrevistadas são solteiros(as) $(89,2 \%)$, mas havendo um índice significativo $(9,5 \%)$ de jovens casados ou vivendo juntos. Coerente com esses dados, a grande maioria deles não possui filhos $(81,8 \%)$. Por outro lado, um número correspondente a quase $\mathrm{o}$ dobro dos casados possuem (18\%), o que evidencia um bom número de jovens que possuem filhos, mas que não moram juntos, fenômeno comum nos casos de gravidez na adolescência, por exemplo.

Outra dimensão que interfere na condição juvenil é a cor/raça. No caso dessa pesquisa, uma grande parte dos entrevistados se classifica como pardos (36,5\%) enquanto $19,3 \%$ deles se classificam como pretos, totalizando $55,8 \%$ dos entrevistados integrantes da raça negra. Finalmente temos $35,1 \%$ dos jovens que se consideram brancos, $5,3 \%$ amarelos e 3,1\% indígenas.

A religião também é constitutiva da condição juvenil e, como veremos posteriormente, ocupa um lugar significativo. No caso dessa pesquisa, a maioria

5 A partir desse momento, os dados se referem à pesquisa de opinião, que foi realizada por amostragem probabilística, tendo como universo uma amostra de 1000 jovens na faixa etária de 15 a 24 anos, sendo $30,1 \%$ deles na faixa etária de 15 a 17 anos, igual porcentagem na faixa de 18 a 20 anos e $39,8 \%$ deles na faixa etária de 21 a 24 anos. A amostra procurou garantir uma certa homogeneidade em relação ao sexo, sendo entrevistados $49,6 \%$ de homens e $50,4 \%$ de mulheres. Destes, $42,2 \%$ integram a classe social C, enquanto $28,1 \%$ integram a classe $\mathrm{D} / \mathrm{E}$ e finalmente $19,8 \%$ integram a classe $\mathrm{A} / \mathrm{B}$. 
dos jovens entrevistados na RMBH se declara católico (61,5\%), seguido pelos evangélicos/protestantes (22,7\%). É interessante notar que um índice significativo de jovens $(9,5 \%)$ declararam que acreditam em Deus, mas não seguem nenhuma religião e apenas $1,6 \%$ deles afirmam não acreditar em Deus.

A pesquisa apontou a existência de $41,7 \%$ dos jovens de 15 a 24 anos na RMBH trabalhando. Desses, a maior parte (37,9\%) tinha carteira assinada; $20,1 \%$ eram empregados sem carteira e 22,3\% declararam-se autônomos. Somando-se os dois últimos índices, verifica-se que há $42,3 \%$ de jovens vivenciando uma situação precária no trabalho, sem comprovação de experiência nem qualificação para melhor inserção no mercado de trabalho. Por outro lado, a desocupação atingia $58,3 \%$ dos entrevistados. Desses, a maioria $(64,5 \%)$ estava procurando trabalho no período da pesquisa.

A sociabilidade é outra dimensão da condição juvenil. Na pesquisa realizada, ela aparece subtendida em duas dimensões nas quais tem uma forte presença: no acesso à cultura e lazer e na participação social em grupos. Quando perguntados sobre os lugares que mais frequentam, a grande maioria dos jovens disse frequentar shoppings $(61,2 \%)$. Em seguida, estão os cinemas, com 47,3\%; seguido de parques e praças, com 44,9\%. Quando é feita a clivagem por classe, verifica-se que quanto mais elevada, maior a frequência em todos os espaços sugeridos. E para os jovens das classes $\mathrm{D} / \mathrm{E}$, parques e praças aparecem em segundo lugar $(47,8 \%)$ atrás apenas dos shoppings.

Perguntados sobre como costumam se informar, a grande maioria dos jovens da RMBH o faz através da televisão (83\%), seguidos pelos jornais e revistas (52,7\%); rádio (49,2\%); amigos, turma ou colegas de trabalho $(24,3 \%)$; internet (21,5\%); familiares $(17,8 \%)$ e finalmente, professores $(13,3 \%)$ e colegas de escola $(11,8 \%)$. É interessante pontuar que, para as novas gerações, a escola deixa de ser o espaço privilegiado de acesso às informações, reforçando a necessidade de repensar a sua função social, principalmente para os jovens. Ao mesmo tempo evidenciam a centralidade dos meios de comunicação para os jovens, sendo um traço cultural característico das contemporâneas culturas juvenis, o que demanda novas pesquisas.

\section{A participação social e política da juventude}

Os dados evidenciam que apenas $20,7 \%$ dos jovens da RMBH participam de qualquer grupo, número que se aproxima de outras pesquisas realizadas sobre 
esse tema. ${ }^{6}$ De uma maneira geral, tal índice é marcado por diferenças nos níveis de participação segundo alguns atributos pessoais (gênero, faixa etária), a escolaridade e a origem social dos jovens. Mas é possível constatar uma tendência em aumentar a participação entre esses das camadas médias e altas, mais novos e com um nível de instrução mais elevado.

Entre os jovens que participam, 43,5\% desenvolvem atividades religiosas e $27,1 \%$ atividades culturais (como música, dança e teatro). Os grupos que desenvolvem atividades esportivas aglutinam $26,6 \%$ dos jovens; atividades estudantis, 12,6\%; e melhoria das condições de vida no bairro, 7,7\%. A partir daí, os índices caem de forma significativa: 4,3\% desenvolvem atividades de comunicação; $3,9 \%$, atividades político-partidárias ou estudantis; $3,4 \%$, meio ambiente e ecologia; e, por último, 0,5\%, trabalhos voluntários.

Fica muito evidente a presença marcante das atividades de lazer e cultura que, somadas, atingem mais da metade dos jovens. O perfil dos que participam dessas atividades aponta uma tendência maior entre as camadas D/E $(34,1 \%)$ do que entre as camadas A/B $(25,6 \%)$. Os dados indicam ${ }^{7}$ uma tendência entre os mais pobres, negros, mais novos e menos escolarizados de se envolverem com atividades culturais, o que demanda maiores investigações.

Apesar de citada por um número menos significativo (7,7\%), a participação em movimentos comunitários indica questões importantes a serem aprofundadas. Nesse caso há uma tendência à participação maior dos jovens mais pobres, negros e mais velhos. Apesar da pequena participação atual, quando perguntados se já haviam participado de algum movimento ou reunião para melhorar a vida do seu bairro ou da sua cidade, os índices sobem para 19,9\%. Uma hipótese a ser investigada nesse caso refere-se a uma possível adesão dos jovens a ações concretas e que apresentem resultados em curto prazo em torno de alguma melhoria no seu local de moradia e que não demandem um envolvimento cotidiano $^{8}$. Esses dados podem nos indicar um possível campo de ação para as

6 Na pesquisa nacional do Projeto Juventude, os índices ficaram próximos: 15\% dos jovens afirmaram participar de grupos enquanto $85 \%$ nunca o fizeram. (ABRAMO; BRANCO, 2005)

7 Há claro predomínio de jovens pretos $(36,1 \%)$, em relação aos pardos $(18,9 \%)$ e brancos (24,7\%), apontando para uma possível relação das expressões culturais, principalmente a música e a dança, com uma matriz cultural africana. Também em relação à idade, a proporção de participação entre os mais novos é maior (34,6\% entre 15 e 17 anos) do que entre os mais velhos $(17,4 \%$ entre 21 e 24 anos). É interessante notar que a presença de jovens com baixa escolaridade é maior (40,4\% com ensino fundamental) do que entre aqueles com o ensino médio $(22,1 \%)$ ou com ensino superior $(23,1 \%)$.

8 Essa hipótese é reforçada quando se observam os objetivos desses movimentos: melhoria no saneamento e meio ambiente $(33,2 \%)$, áreas de lazer e quadras de esporte $(31,2 \%)$, questões relacionadas à educação e à escola $(28,6 \%)$, segurança $(26,6 \%)$ e postos de saúde $(25,6 \%)$. 
escolas públicas, uma vez que os jovens se mobilizaram em torno de questões que podem se constituir em possível canal de diálogo com a comunidade.

Durante a sua fase quantitativa, foram apresentadas às pessoas entrevistadas algumas atitudes típicas de participação política, diante da qual ele deveria se posicionar. ${ }^{9}$ A maioria delas $(57,6 \%)$ concordou que procura se informar sobre a política, mas sem participar. Apenas $8 \%$ consideram-se politicamente participantes e 31,8\% assumem que não procuram se informar sobre o tema nem participar pessoalmente. Esses índices confirmam que existe certo interesse por parte da juventude em se informar sobre a realidade política. Por outro lado, há um esvaziamento da participação nas instâncias políticas, talvez motivada pelo descrédito na atuação dos políticos e seus partidos presente na opinião pública brasileira no momento da pesquisa. No caso da juventude, é importante destacar que essa postura é alimentada pela falta de estímulo à participação juvenil nas diferentes instâncias, como nos partidos, nos sindicatos e nas administrações públicas.

Para melhor aferir as representações dos jovens em torno da participação e da política, foram apresentadas algumas frases, pedindo-lhes que se posicionassem diante de cada uma delas. ${ }^{10}$ Os entrevistados pareceram divididos entre uma postura de adesão e valorização das causas coletivas e o reforço de soluções individualistas. Em geral os jovens tenderam a reproduzir imagens negativas dos políticos e da sua atuação muito presentes no senso comum, que se revelava numa postura distanciada e pré-concebida em relação ao mundo da política tradicional.

Essas representações ficaram evidentes nos Grupos de Diálogo, quando tenderam a recusar a possibilidade de se engajarem em formas tradicionais de participação política tais como os partidos, os sindicatos, o movimento estudantil ou outros movimentos sociais. Embora reconhecendo a sua importância em termos de eficácia para atender às demandas sociais, os jovens pareceram compreender esse tipo de participação como uma ação institucional do governo e não como uma atuação dos jovens em outras articulações como movimento estudantil, grêmios, etc. Temos como hipótese que o pouco conhecimento dos

9 As atitudes a serem escolhidas foram: 1. Considero-me politicamente participante. 2. Procuro me informar sobre a política, mas sem participar pessoalmente. 3. Não procuro me informar sobre a política nem participar pessoalmente.

10 Os jovens foram solicitados a dizer se concordavam totalmente, concordavam parcialmente, discordavam parcialmente ou discordavam totalmente com as seguintes frases: "A maioria dos políticos não representa os interesses da população"; "A maioria dos políticos só defende os seus interesses pessoais"; "É preciso abrir canais de diálogo entre os cidadãos e o governo"; "É preciso que as pessoas se juntem para defender seus interesses" e "Cada pessoa tem que cuidar de seus próprios interesses". 
jovens sobre o que vem a ser a "vida política" e a sua pouca inserção em ações coletivas possa ser um dos motivos dessa leitura restrita.

Parece-nos também que os jovens indicam que o caminho da participação política mais organizada pertence ao mundo adulto e, mais ainda, a um determinado tipo de engajamento político mais tradicional, reduzindo a participação política a uma ação reivindicativa junto às instituições constituídas como a Câmara Municipal, os vereadores ou administração municipal. Podemos inferir que os jovens, de uma maneira geral, não se percebem como atores, sujeitos de uma ação que possa interferir na sua realidade e nas instituições. Isso parece demonstrar certa descrença nas formas de engajamentos políticos mais tradicionais, falta de um conhecimento mais amplo sobre a vida política e a pouca experiência dos jovens em ações como essas. Mas também nos alerta para uma visão muito restrita das possibilidades de intervenção na sua realidade como atores, sujeitos e cidadãos.

A tensão entre a valorização positiva da ação coletiva e a descrença na eficácia do engajamento social e político parece expressar-se na tendência a escolher como sendo ideais as formas de atuação política que combinam a ação voluntária por meio da atuação em agrupamentos juvenis. Os participantes viram as ações voluntárias, quase sempre por meio das suas formas coletivas, como o caminho possível para conquistar as suas demandas. Ficou claro nos debates que eles têm consciência dos limites deste tipo de envolvimento participativo, mas admitem que "já é alguma coisa". Nas argumentações também ficou perceptível que este caminho era o mais flexível em relação à disponibilidade de tempo e ao grau de envolvimento exigido, possibilitando níveis diferenciados de adesão. Outro aspecto é o fato deste tipo de ação produzir resultados imediatos e visíveis, além de ser o que possibilita um controle direto das ações.

A ênfase no voluntariado pode ser uma expressão da falta de canais nos quais os jovens experimentam, de formas diferenciadas de participação social, o que resulta em um descrédito na efetividade das ações coletivas. Ela expressa também uma visão assistencialista da solidariedade, em que as ações voluntárias, como expressão cultural, são naturalizadas como uma consequência das "boas intenções" dos jovens. Finalmente, essa adesão pode ser creditada à forma como a juventude contemporânea vem lidando com as dimensões do tempo. $\mathrm{O}$ voluntariado como uma ação que tem algum resultado imediato, visível e até certo ponto passível de controle, pode estar expressando o tempo e ritmo da juventude contemporânea (DAYRELL, 2005).

Esses dados demandam compreender melhor o posicionamento dos jovens diante da realidade nacional e as perspectivas que apontam para uma inserção ativa na vida social e política do país. Consideramos igualmente importante refletir sobre o papel da escola neste contexto, visto que ela é uma das poucas 
instituições públicas que atingem de forma mais universal a juventude brasileira. Que possível relação podemos estabelecer entre a participação juvenil e a escola pública? Quais são os limites e as possibilidades dessa instituição frente à condição social dos jovens brasileiros?

\section{Participação juvenil: algumas reflexões}

Conforme indicado anteriormente, buscamos aqui evitar conclusões pessimistas e superar as idealizações do passado em torno da participação juvenil. Se os índices não permitem fazer comparações com gerações passadas, da mesma forma são muito poucos os dados sobre a participação sociopolítica do conjunto da população, o que torna difícil saber se a juventude é o único segmento que não apresenta maiores índices de participação ou se essa realidade refere-se a toda a população. Considerando os dados de Ribeiro e Santos citados(apud DAYRELL; GOMES; LEÃO, 2005), os índices de participação não diferem muito entre jovens e adultos. Segundo esses autores, os níveis de instrução e de rendimento parecem interferir mais nas possibilidades de associação, coincidindo com o perfil encontrado na pesquisa.

Podemos dizer que uma hipótese para explicar os baixos índices de participação social e política dos jovens da RMBH é o contexto socioeconômico vivenciado pela maioria deles, que não estimula a esperança e a crença na ação coletiva como capaz de interferir de algum modo na sua realidade. Esse contexto também não oferece os meios para a criação de hábitos e valores favoráveis à participação nem mesmo para o seu exercício e consequente aprendizagem, levando-nos a concluir que a democracia política é muito difícil de efetivar-se sem um mínimo de igualdade de condições de vida. A esse quadro soma-se a falta de espaços e de situações as quais os jovens da RMBH encontram para o exercício e aprendizagem da vida coletiva e da participação social, experimentação essa que poderia levá-los a acreditar nos possíveis resultados de uma ação coletiva.

Outro aspecto importante a ser considerado refere-se ao tempo e ao ritmo da juventude contemporânea, conforme indicado anteriormente. Algumas pesquisas evidenciam que a participação juvenil tem se caracterizado pela fluidez, pelo nomadismo e pela intermitência, além de sinalizar para formas de agregação pontuais, com objetivos determinados e no presente. Essas características têm relação com as transformações mais amplas introduzidas no contexto das sociedades complexas, como a velocidade das transformações tecnológicas, que ampliam as incertezas características desse nosso tempo (LECCARDI, 1991). Assim, pode-se afirmar que os espaços e estímulos ao 
exercício e aprendizagem da participação, bem como a relação que os jovens têm com o tempo são variáveis que interferem no seu envolvimento efetivo nas instâncias sociais e políticas.

Uma última reflexão diz respeito ao tipo de grupo e de atividade com os quais os jovens estão envolvidos. Pode-se levantar uma hipótese, já veiculada em artigos e debates, que vem ocorrendo um processo participativo que simultaneamente se afasta dos espaços políticos formais, mas adensa a esfera pública em outros tipos de ações coletivas. Conforme mostram os dados da pesquisa, há um esvaziamento das instâncias políticas clássicas, como os partidos e sindicatos e até mesmo o movimento estudantil como espaços privilegiados da participação juvenil. Parece haver, por parte dos jovens, uma negação dessas formas tradicionais de participação, principalmente quando elas são dominadas pelos vícios do clientelismo e do nepotismo. Esse parece ser um fenômeno também constatado em outros países. No caso da Europa, por exemplo, algumas pesquisas evidenciam o afastamento dos jovens dos sindicatos, mas não a sua negação; a desconfiança em relação aos partidos, mas o reconhecimento de um interesse difuso sem a participação correspondente; e a busca de uma política sem rótulos tradicionais que designam posições de direita e esquerda (SPOSITO, 2000; BENDIT, 2000).

Ao mesmo tempo, os jovens se mostram mais envolvidos, além das atividades religiosas, com grupos e associações ligados ao lazer e à cultura, o que pode apontar para um alargamento dos interesses e práticas coletivas juvenis que fomentam mecanismos de aglutinação de sociabilidades, de práticas coletivas e de interesses comuns. Tais ações apontam para a questão da identidade juvenil e o direito a vivenciar a própria juventude como mobilizadores de uma possível participação social. Além disso, novas formas de ação e novos temas parecem se articular em torno de ações coletivas que se dão de múltiplas formas e com níveis diversos de intervenção no social, muitas vezes de uma maneira fluida e pouco estruturada.

Tendo em vista a condição social da juventude brasileira, suas experiências de participação e as suas representações sobre o mundo da política discutidas anteriormente, cabe nos perguntarmos sobre o papel da escola, sobretudo a pública, em relação ao tema. Em que medida a instituição escolar fomenta experiências que estimulam o aprendizado e a experimentação em torno da participação social e política? A organização escolar em sua forma e conteúdo tem priorizado uma formação que permite aos jovens se posicionarem criticamente diante da realidade e vislumbrarem formas de ação coletiva em torno de suas demandas? Ela se preocupa em estimular a participação na gestão escolar e a organização autônoma dos estudantes? Tendo como foco a participação social e política, qual lugar a escola ocupa na vida dos jovens? 


\section{Escola e participação juvenil}

Os dados sobre a escola revelam que tal instituição não está ausente da vida dos jovens, principalmente das classes D e E. No entanto, observa-se que apenas $32,4 \%$ possuem o Ensino Médio completo, contra 45,8\% que não completaram esse nível de ensino e ainda $21,8 \%$ que só possuem o Ensino Fundamental. É preciso observar ainda que $54,5 \%$ dos pesquisados não estavam estudando no momento da pesquisa, o que nos permite afirmar que ainda estamos longe de garantir a universalização do acesso à escola para os jovens.

Além da visível desigualdade quanto ao acesso à educação, devemos nos perguntar que escola é essa que os jovens frequentam, mesmo que seja de forma acidentada? Ela consegue se organizar para atender esses sujeitos na sua condição juvenil? A pesquisa quantitativa mostrou que menos de $50 \%$ das escolas oferece atividades coletivas que estimulem a participação, sejam elas públicas ou particulares. As ações comunitárias ou os trabalhos sociais consistiram em atividades menos presentes sem apresentar diferenças significativas em termos da classe social de origem, do grau de instrução ou tipo de escola. Infere-se com isso que a escola não vem estimulando nem tem sido espaço de práticas coletivas de solidariedade para seus alunos.

Em relação às atividades culturais na escola nota-se que apenas 33,6\% dos jovens entrevistados afirmaram existir tais atividades nas instituições que frequentam. Praticamente dois terços das escolas na RMBH não estimularam ou organizaram ações culturais em 2004, o que evidencia um distanciamento da escola em relação à realidade juvenil. Se a vivência de tais expressões faz parte das práticas juvenis, a escola que atende a esse público não deveria incluí-las na sua organização, nos seus tempos e espaços escolares?

Além desse baixo índice, chama atenção o fato de que as atividades culturais (tais como as festas, entre outras) são mais presentes nas escolas frequentadas pelos jovens das classes D/E (35,8\%) em relação aos(às) jovens das classes A/B $(30,7 \%)$, bem como entre aqueles que estudam em escolas públicas $(34,7 \%)$ quando confrontados com os que estudam em escolas particulares (26,6\%). Ao mesmo tempo, tais atividades são mais presentes entre os alunos que frequentam o Ensino Fundamental $(35,4 \%)$ ou Médio $(36,3 \%)$ do que entre aqueles que estão no Ensino Superior (23,7\%).

Podemos fazer algumas inferências sobre as possibilidades de participação acima apresentadas. $\mathrm{O}$ fato de as escolas frequentadas pelos jovens das classes $\mathrm{D} / \mathrm{E}$ realizarem mais atividades culturais do que aquelas frequentadas pelos jovens das classes A/B pode estar relacionado com a ausência de equipamentos públicos de lazer e de cultura nas comunidades pobres. Nesse caso, a 
escola passa a ser um dos poucos espaços públicos no qual a juventude pobre pode realizar tais atividades.

Assim, apesar das condições adversas, a escola pública ainda pode ser considerada como um espaço de realização de atividades coletivas para a juventude pobre possibilitando algum nível de participação juvenil. As questões que se colocam então são: como essas atividades são desenvolvidas? Quem são os jovens que delas participam? Essas escolas conseguem dialogar com o mundo da produção cultural juvenil existente no seu entorno, articulando-o com as sua vivências escolares?

Outra inferência que podemos fazer diz respeito à diminuição destas atividades quanto mais elevado o grau de ensino. Quanto mais inserido no mundo do "pensar" como tradicionalmente se atribui ao Ensino Superior e do "fazer" como é costume atribuir à vida adulta, mais a escola diminui a sua presença enquanto espaço cultural, de lazer e de possibilidade de ações coletivas, transformandose em uma instituição cada vez mais livresca e com ênfase nos conteúdos. No entanto, cabe aqui ressaltar que essa tendência pode sofrer alterações ao se tratar de universidades públicas e privadas, o que poderia dar margem a outro tipo de interpretação.

É importante ressaltar, ainda, que a constatação da existência das atividades culturais, de lazer e das festas nas escolas, majoritárias nas escolas públicas onde estão alunos das camadas C, D e E, não nos informa a respeito da qualidade delas. Muitas vezes tais atividades são utilizadas como forma de ocupar o tempo na escola, não contribuindo de fato para a ampliação do capital cultural dos jovens, principalmente dos pobres. Parece-nos que essas escolas tendem a explorar mais o campo das relações com objetivos de controle da disciplina e formação de hábitos em detrimento de potencializar relações humanas mais dignas.

Já as atividades de cunho mais informativo revelaram uma tendência oposta. A pesquisa revela que algumas práticas, como filmes, debates, seminários, visita a museus e exposições, apresentaram índices proporcionalmente maiores nas escolas dos alunos oriundos das camadas $\mathrm{A} / \mathrm{B}$ do que entre aquelas frequentadas por alunos das classes D/E. Da mesma forma, estas foram atividades proporcionalmente mais presentes nas escolas privadas de Ensino Superior do que nas públicas e de ensino básico. Esses dados parecem mostrar uma tendência das escolas particulares em privilegiar mais as atividades de cunho acadêmico do que aquelas culturais ou de sociabilidade. Esse dado revela que a maioria das escolas frequentadas pelos jovens, sobretudo os pobres, não realizam ou exercem de forma precária, atividades que podem ser consideradas básicas em um processo de ensino aprendizagem de qualidade. Coloca-se em questão o eixo do trabalho pedagógico destas instituições, o qual parece voltar-se mais para atividades escolares circunscritas aos muros da escola do que a articulação com 
o mundo externo. Além disso, podemos indagar sobre as condições físicas e a presença ou não de equipamentos tecnológicos que possibilitem, por exemplo, a exibição de vídeos, trabalhos ligados ao uso da internet, entre outros.

A realização de debates no interior das escolas também merece a nossa atenção. Sabemos que essas atividades, quando realizadas com competência, podem se tornar um profícuo canal de informação e um espaço de aprendizado do exercício da argumentação, da discussão, da troca de opiniões, etc. Estas ações foram realizadas, com contornos e intensidade muito variados nas escolas públicas e particulares. Os resultados da pesquisa evidenciam que estas não foram atividades centrais no fazer pedagógico das escolas frequentadas pelos jovens, no entanto, quando estas foram desenvolvidas abarcaram os seguintes temas: a questão político-eleitoral, Aids, sexualidade, drogas, violência, direitos humanos, projeto político-pedagógico da escola, regras, disciplina e formas de avaliação e, por último, a questão urbana, como os problemas do bairro e da cidade.

A análise dos dados sugere que as escolas se mostram pouco abertas a desenvolver atividades que vão além da transmissão dos conteúdos formais. A existência desses espaços é precária, poucas escolas criam espaços e situações que favoreçam a experiência da solidariedade, o fortalecimento da sociabilidade, o acesso a atividades culturais e mesmo ao conhecimento de forma mais participativa, como os debates e seminários.

No entanto, os dados sobre as escolas particulares, sobretudo, aquelas frequentadas pela classe média trouxeram novas questões, ou pelo menos, abrem a possibilidade de compreensão de que, no contexto da condição juvenil, ser jovem pobre e aluno de escola pública possibilita outras formas de vivência e de expressão desta condição quando comparado com o ser jovem da classe média e de escola privada. A inclusão das dimensões de gênero e de raça pode nos indicar outro quadro da condição juvenil, bem como da própria relação juventude, escola e participação juvenil.

Outra questão importante refere-se à frequência à escola nos finais de semana. Constatou-se que apenas $14,2 \%$ dos jovens da RMBH frequentam as escolas ou universidades nos finais de semana. Algumas hipóteses para essa baixa participação podem ser a não abertura nos finais de semana, a desinformação dos jovens sobre o uso do espaço da escola nesses momentos e o desinteresse em participar de ações como essas. A constatação ou não dessas inferências demandaria uma pesquisa mais aprofundada em que aspectos como nível socioeconômico e o pertencimento étnico-racial e de gênero fossem considerados.

Os dados apontam alguns caminhos na relação entre escola, juventude e participação juvenil. As atividades extraclasse, quando bem organizadas e compreendidas como um direito do aluno e da sua família, podem resultar em outra forma de organização da escola, sobretudo a pública, que administra 
melhor o tempo e o espaço escolar e a relação com a comunidade. Existem no entorno da escola, ONGs, movimentos sociais, grupos culturais juvenis, entre outros, que podem ser chamados como parceiros nesse trabalho. Não se trata aqui de projetos sociais e projetos governamentais de abertura da escola nos finais de semana. Para além destes, que não atingem todas as escolas, poderiam ser articulados projetos específicos, como a capacitação de agentes culturais que atuem no tempo livre e articulem os conteúdos escolares com as diferentes propostas culturais.

Por fim, alguns dados da pesquisa dizem respeito ao lugar ocupado pela escola nas preocupações dos jovens, que apresentaram demandas concretas em relação à escola. Uma delas refere-se à melhor qualificação dos professores, principalmente, no que diz respeito ao desenvolvimento de uma relação humana e pedagógica mais próxima com os alunos, o que se sobrepõe ao reconhecimento da necessidade de mais verbas para a educação.

Durante a realização dos cinco Grupos de Diálogo o sentimento de indignação e decepção em relação à escola foi algo marcante. Os jovens denunciaram um tipo de relação humana e pedagógica baseada no desrespeito e no desprezo aos sujeitos da educação e demandaram outra postura por parte da escola e dos docentes. Isso indica que parece haver um choque cultural, geracional e um desrespeito ao aluno como sujeito social e cidadão de direitos no interior das escolas. Ora, se a relação pedagógica, enquanto relação humana e profissional vai mal, como a escola poderá despertar o interesse dos jovens para uma maior participação e para o usufruto das possíveis alternativas de reorganização dos tempos e espaços escolares por ela apresentada? Como conseguirá envolvê-los nos projetos de trabalho? Como conseguirá estimular a sua participação nas diferentes instâncias democráticas no interior da instituição?

\section{Considerações finais}

A pesquisa realizada apresenta os caminhos, as possibilidades e os problemas que os e as jovens encontram para viabilizar a sua participação na sociedade, ainda tímida diante da potencialidade de ação presente na condição juvenil. Um dos motivos possíveis da pouca participação social da juventude pode ser creditado à falta de espaços e de situações para o exercício e aprendizagem da vida coletiva e da participação social, experimentação essa que poderia levá-los a acreditar nos possíveis resultados de uma ação coletiva. Parece existir uma falta de sensibilidade do mundo adulto e suas instituições em criar espaços insti- 
tucionais, além da escola, que estimulem a participação dos jovens e o desenvolvimento de valores democráticos.

A escola, como se afirmou anteriormente é um dos espaços privilegiados para o processo de aprendizagem de formas e mecanismos de participação. Mas nos Grupos de Diálogo da segunda fase da pesquisa, chamou-nos a atenção o fato dos jovens, com pouquíssimas exceções, não se referirem às organizações estudantis, nem mesmo apresentarem demandas ou propostas relacionadas à participação nesta modalidade.

Parece que a escola, tanto a pública quanto a privada, não tem priorizado a questão da participação como uma dimensão importante do processo educativo vivenciado pelos jovens e nem mesmo os tem informado a respeito da existência dessas instâncias. Uma resposta fácil diante desses dados é atribuir o problema aos alunos, considerando-os desinteressados ou apáticos. No entanto, quando a escola oferece atividades diferenciadas, os alunos e as alunas tendem ao envolvimento. Na metade das instituições que oferecem as atividades mencionadas anteriormente, há uma participação significativa de mais de $60 \%$ dos alunos.

Muitos estudos apontam a necessidade de organizar os tempos e os espaços escolares de uma forma flexível e de construir projetos político-pedagógicos que dialoguem com os sujeitos da escola e não somente com os órgãos administrativos. No caso da escola voltada para as camadas populares, que vive cotidianamente situações concretas de privação, desigualdade social e desemprego, aponta-se uma necessidade ainda maior dessa flexibilidade. Ou seja, a educação, enquanto direito social, não deveria reproduzir as mesmas condições e relações vividas pelos sujeitos no contexto das desigualdades sociais. Também não deveria reproduzir o viés da desigualdade entre o público e o privado vivido historicamente pela população brasileira no seu dia a dia. No entanto, de fato o exercício do direito à educação nas relações cotidianas da escola, na organização do currículo, nas atividades extraclasse e nas possibilidades de participação ainda não se efetivou. Não podemos negar que iniciativas nessa direção existem, mas elas ainda não representam a maioria das ações pedagógicas.

É importante ponderar que existe uma relação entre a efetivação da participação juvenil e o lugar ocupado pela juventude na sociedade, na família e nas políticas públicas. A escola, sozinha, apresenta dificuldades para construir e reconstruir espaços significativos de participação. Com ela disputam e convivem projetos sociais, movimentos culturais juvenis, as necessidades da sobrevivência, a desigualdade e a violência. Nem sempre esta instituição consegue levar em consideração essa dinâmica e as mudanças que a mesma impõe aos espaços formadores presentes na sociedade atual. Trata-se de um processo complexo no qual a juventude está inserida. 
A escola revelada na pesquisa ainda não é a escola desejada e esperada pelos jovens, principalmente os pobres. No entanto, eles estão lá e precisam ser vistos, ouvidos e considerados para além dos estereótipos sobre a juventude já construídos social e culturalmente. Não basta "descobrir" que, apesar dos problemas, uma parte da juventude brasileira frequenta a escola. É preciso desvelar como e em que condições essa frequência se dá, indo além do recorte do desempenho escolar e investigando como se dá a construção das redes de sociabilidade e as possibilidades concretas de participação vividas por eles dentro e fora da escola.

Apesar desses desafios, não cabe à escola omitir-se da sua responsabilidade de mudança. Sendo um dos poucos espaços em que a maioria da juventude pesquisada transita, essa instituição é desafiada a construir outro tipo de organização do trabalho pedagógico e a rever suas instâncias de participação considerando não somente o mundo adulto, mas, também, as temporalidades humanas com as quais convive.

\section{REFERÊNCIAS}

ABRAMO, Helena Wendel; BRANCO, Pedro Paulo Martoni. Retratos da Juventude Brasileira: Análises de uma pesquisa nacional. São Paulo: Instituto Cidadania; Editora Fundação Perseu Abramo, 2005.

BENDIT, René. Participación social y política de los jóvenes en países de la Unión Europea. In: BALARDINI, Sergio (Comp.). La participación social y política de los jóvenes en el horizonte del nuevo siglo. Buenos Aires: CLACSO, 2000. p. 19-58.

BRENNER, Ana Karina; CARRANO, Paulo; DAYRELL, Juarez. Juventude brasileira: culturas do lazer e do tempo livre dos jovens brasileiros. In: ABRAMO, Helena; BRANCO, Pedro Paulo Martoni. Retratos da Juventude Brasileira: análises de uma pesquisa nacional. São Paulo: Editora Fundação Perseu Abramo, 2005

DAYRELL, Juarez T.; GOMES, Nilma L.; LEÃO, Geraldo M. P. Juventude Brasileira e Democracia: participação, esferas e políticas públicas. Região Metropolitana de Belo Horizonte. Relatório Preliminar dos Grupos de Diálogos. Belo Horizonte, junho, 2005. 
IBASE. Juventude brasileira e democracia: participação, esferas e políticas públicas. Marco Zero, jul. 2004. Mimeo.

IBASE. Juventude brasileira e democracia: participação, esferas e políticas públicas. Relatório Global. Rio de Janeiro: Ibase e Polis, janeiro de 2006.

LECCARDI, Carmem. Orizzonte del tempo: esperienza del tempo e mutamento sociale. Milano: Franco Angeli, 1991.

MARGULIS, Mário. La juventud es más que una palabra. In: MARGULIS, M.(Org.) La juventud es más que una palabra. Buenos Aires: Editorial Biblos, 2000 .

MELUCCI, Alberto. Juventude, tempo e movimentos sociais. Juventude e contemporaneidade. Rev. Brasileira de Educação, São Paulo, n. 5/6, p. 5-14, maio-ago./set.-dez. 1997. Edição Especial.

PERALVA, Angelina. O jovem como modelo cultural. Revista Brasileira de Educação, São Paulo, ANPED, n. 5/6, 1997.

SPOSITO, Marilia. Algumas hipóteses sobre as relações entre movimentos sociais, juventude e educação. Revista Brasileira de Educação, ANPED, n. 13, 2000.

Texto recebido em 01 de dezembro de 2008.

Texto aprovado em 29 de dezembro de 2008. 